\title{
Exploring the feasibility of targeted Chronic Hepatitis B screening in the Emergency Department: a pilot study
}

\author{
Dr Catherine Brock|, BSc MD \\ Position: HMO1, Austin Health \\ Institutional affiliation: Austin Clinical School, Department of Medicine, University \\ of Melbourne
}

\section{Dr Yuan Yi, BBiomed MD}

Position: HMO2, Royal Melbourne Hospital

Institutional affiliation: Austin Clinical School, Department of Medicine, University of Melbourne

\section{Dr Timothy Papaluca, MBBS FRACP}

Position: Gastroenterology Research Fellow, St Vincent's Health Melbourne Institutional affiliation: Department of Gastroenterology and Hepatology, Austin Health

\section{Benjamin Lucas, BSc M.Analytics}

Position: Master of Analytics student, Royal Melbourne Institute of Technology

This is the author manuscript accepted for publication and has undergone full peer review but has not been through the copyediting, typesetting, pagination and proofreading process, which may lead to differences between this version and the Version of Record. Please cite this article as doi:

This article is protected by copyright. All rights reserved. 
Institutional affiliation: Department of Geospatial Sciences and Mathematics, Royal Melbourne Institute of Technology

\title{
Professor Peter W Angus, BS MB PhD
}

Position: Medical Director, Liver Transplant Unit, Austin Health

Institutional affiliation: Department of Medicine, University of Melbourne;

Department of Gastroenterology and Hepatology, Austin Health

\section{Professor David Taylor, MBBS MD MPH DRCOG FACEM}

Position: Director of Emergency Medicine Research, Austin Health

Institutional affiliation: Department of Medicine, University of Melbourne;

Department of Emergency Medicine, Austin Health

\section{Dr Christopher Leung, MBBS FRACP PhD}

Position: Gastroenterologist, Austin Health

Institutional affiliation: Department of Medicine, University of Melbourne;

Department of Gastroenterology and Hepatology, Austin Health

\begin{abstract}
Author contributions: Brock $\mathrm{C}$ assisted in the design of the study, performed data collection, was involved with data analysis, and drafted the manuscript; Yi Y assisted with study design and data collection; Papaluca T was involved with data collection; Lucas B performed statistical analysis; Angus P participated in oversight of the study;
\end{abstract}

This article is protected by copyright. All rights reserved. 
Taylor D assisted with oversight of the study, as well as study design, data analysis and manuscript draft; Leung $\mathrm{C}$ assisted with oversight of the study, as well as study design, data analysis and manuscript draft. The final manuscript has been read and approved by all authors.

Running title: Targeted Chronic Hepatitis B screening in ED

Research carried out at: Austin Health, 145 Studley Rd, Heidelberg, Victoria, Australia, 3084.

Correspondence to: Dr Catherine Brock. BSc, MD

Austin Health, 145 Studley Rd, Heidelberg, Victoria, Australia, 3084.

Email: catherine.brock3@gmail.com | Telephone: +61 394965000

\section{Word count}

Abstract: 100

Main text: 750

\section{ABSTRACT}

This article is protected by copyright. All rights reserved. 


\section{Objective:}

To explore the feasibility of an ED chronic hepatitis B (CHB) screening program.

\section{Methods:}

Adult patients born in intermediate-high CHB prevalent regions completed a prescreening questionnaire and were offered CHB testing. ED staff were surveyed to gauge potential barriers to the program.

\section{Results:}

The 80 patients demonstrated limited knowledge of HBV transmission and perceived many barriers to screening. Among 65 tested for CHB, no new cases were detected but $36(55.4 \%, 95 \%$ CI $42.6-67.5)$ were susceptible to infection. Staff supported the program but reported potential barriers.

\section{Conclusion:}

Targeted ED CHB screening is feasible but effectiveness and cost-effectiveness need further exploration.

Key words: Chronic hepatitis B (CHB), Emergency Department (ED), Hepatitis B virus (HBV), Public health, Targeted screening 


\section{INTRODUCTION}

An estimated 233,000 people are living with Chronic Hepatitis B (CHB) in Australia ${ }^{1}$. Over half of these cases occur in migrants from countries with intermediate $(2-8 \%)$ or high (>8\%) prevalence of Hepatitis B surface antigen (HBsAg) $(44 \%)$ or the Indigenous population $(11 \%)^{1}$. In the Australian-born non-Indigenous and Indigenous populations, the prevalence is $0.2 \%$ and $3.7 \%$, respectively. For those born in the predominantly intermediate-high risk regions of Northeast and Southeast Asia, the prevalence is $6.2 \%$ and $4.5 \%$, respectively ${ }^{1}$.

More than one-third of persons infected are unaware of their disease status ${ }^{1}$. The ED could provide opportunistic screening especially for migrant groups, which tend be over-represented in $\mathrm{EDs}^{2}$. We explored the feasibility of ED CHB screening of individuals at high risk.

This article is protected by copyright. All rights reserved. 


\section{METHODS}

We undertook an observational study in a quaternary hospital ED (April-May 2016) that was approved by the hospital Human Research Ethics Committee.

During office hours, adult patients born in a country with an intermediate-high prevalence of $\mathrm{HBsAg}^{3}$ were included if able to provide informed written consent in English. Participants completed a questionnaire based on pre-existing questionnaires ${ }^{4}$ and tested for content and face validity by samples of the institution's gastroenterologists and patients, respectively. Participants underwent the CHB screening panel of HBsAg, surface antibody (anti-HBs) and core antibody (anti-HBc). A gastroenterologist telephoned patients within one week of discharge to discuss results and follow-up.

A convenience sample of ED medical staff were surveyed regarding the CHB screening program using a questionnaire developed by the hospital's hepatology and ED consultants. The survey was voluntary and anonymous. 


\section{RESULTS}

Eighty patients were enrolled (Figure 1). Forty-five were male (56.3\%, 95\%CI 44.767.2), mean (SD) age was 54 (18) years, and the birthplaces were the Western Pacific (30 participants), Eastern Mediterranean (18), South East Asia (14), Africa (10) and Europe (8).

Most participants were aware that $\mathrm{CHB}$ can cause liver failure and cancer (65) and that HBV can be transmitted through contaminated blood (71) and needles (72). However, 27 were unaware that HBV could be sexually transmitted and 36 incorrectly identified sharing meals as a risk factor.

Sixty-five participants were CHB screened. None was seropositive for HBsAg, hence no new cases were detected. Eighteen were solely HBsAb seropositive indicating immunity through vaccination. Thirty-six were seronegative for HBsAg, HBsAb and $\mathrm{HBcAb}$ and therefore likely susceptible to infection; however, rarely, HBsAb may not be measurable in vaccinated persons. Nine were $\mathrm{HBsAb}$ and $\mathrm{HBcAb}$ seropositive suggesting past exposure. Two were only $\mathrm{HBcAb}$ seropositive indicating past exposure or a false positive.

Among those screened, 22 did not know their vaccination status. Of these, 16 were likely susceptible to infection. Thirty-three participant responses were concordant 
with their serology, with 11 aware of previous vaccination and 22 knowingly unvaccinated. Eight responses were discordant, with one patient unknowingly vaccinated and seven unknowingly not immune. The majority (56/80) would receive the HBV vaccination if advised.

Of the 80 participants and 32 staff surveyed, many agreed that the proposed items presented to both groups were potential barriers to screening. This was especially so for the ED staff (Figure 2). However, 26 staff were neutral or agreed that ED-based CHB screening could be implemented. 


\section{DISCUSSION}

Our participants were generally receptive to CHB screening which may identify those who would benefit from vaccination. Indeed, over half of our participants were susceptible to HBV infection, with self-report of HBV vaccination status often unreliable.

The participants reported culture, language, time and stigma as the main barriers to screening. These barriers could potentially be mitigated through community education. Although cost was also reported, the test is free for patients with a Medicare card ${ }^{5}$. Some participants had concerns that a CHB diagnosis may prevent them from attaining permanent residency. The Migration Health Requirement states that applications may be rejected if individuals are diagnosed with a condition, such as $\mathrm{CHB}$, that exceeds the 'significant cost threshold" ${ }^{6}$. Consent for CHB screening would require appropriate patient counselling.

The participants were aware of the major modes of HBV transmission. However, many were unaware that sexual transmission is possible and that food transmission is not. These findings support the need for community education.

The staff were more likely to report barriers to screening. This may relate to the perceived impact upon their workload or a better understanding of the potential 
consequences of a CHB diagnosis (permanent residency, insurance). Few were opposed to ED screening.

\section{CONCLUSION}

Emergency department screening of high-risk individuals is feasible with patients and staff receptive to the initiative. However, as no new CHB cases were detected, further research is required to determine effectiveness and cost-effectiveness.

This article is protected by copyright. All rights reserved. 


\section{ACKNOWLEDGEMENTS}

We acknowledge assistance from the Austin Health Liver and Gastroenterology Research Group, Kaye Marion from the RMIT Department of Mathematical and Geospatial Sciences for statistical support, and the participants and ED staff.

There are no competing interests, financial or otherwise, to disclose.

This article is protected by copyright. All rights reserved. 


\section{REFERENCES}

1. Kirby Institute. HIV, viral hepatitis and sexually transmissable infections in Australia: Annual Surveillance Report 2017. Sydney: UNSW, Kirby Institute; 2017 2017.

2. Hargreaves S, Friedland JS, Gothard P, Saxena S, Millington H, Eliahoo J, et al. Impact on and use of health services by international migrants: questionnaire survey of inner city London A\&E attenders. BMC Health Serv Res. 2006; 6:153.

3. Centre for Disease Control. Recommendations for Identification and Public Health Management of Persons with Chronic Hepatitis B Virus Infection [homepage on the Internet]. Atlanta: Centre for Disease Control [updated 19 Sep 2008; cited 5 Feb 2016]. Available from:

https://www.cdc.gov/mmwr/preview/mmwrhtml/rr5708a1.htm.

4. Ha NB, Trinh HN, Nguyen TT, Leduc TS, Bui C, Ha NB, et al. Prevalence, risk factors, and disease knowledge of chronic hepatitis B infection in Vietnamese Americans in California. J Cancer Educ. 2013; 28(2):319-24.

5. Department of Health. Second National Hepatitis B Strategy 2014-2017 [homepage on the Internet]. Canberra: Commonwealth of Australia [updated $14 \mathrm{Jul}$ 2014; cited 6 Jun 2016]. Available from:

http://www.health.gov.au/internet/main/publishing.nsf/content/ohp-bbvs-hepb.

This article is protected by copyright. All rights reserved. 
6. Australian Government: Department of Immigration and Border Protection.

Significant health care and community service costs [homepage on the Internet].

Canberra: Australian Government [updated 2017; cited 22 Feb 2017]. Available from:

https://www.border.gov.au/Trav/Visa/Heal/overview-of-the-health-

requirement/significant-costs-and-services-in-short-supply.

This article is protected by copyright. All rights reserved. 


\section{FIGURE LEGENDS}

Figure 1. Summary of patient recruitment and chronic hepatitis B serology results. (CHB, chronic hepatitis B)

Figure 2. Proportions of Emergency Department staff who agreed/strongly agreed regarding barriers to chronic hepatitis B screening. (ED Emergency Department, CHB chronic hepatitis B, Chi square comparisons reported) 
Figure 1. Summary of patient recruitment and chronic hepatitis B serology results. (CHB, chronic hepatitis B)

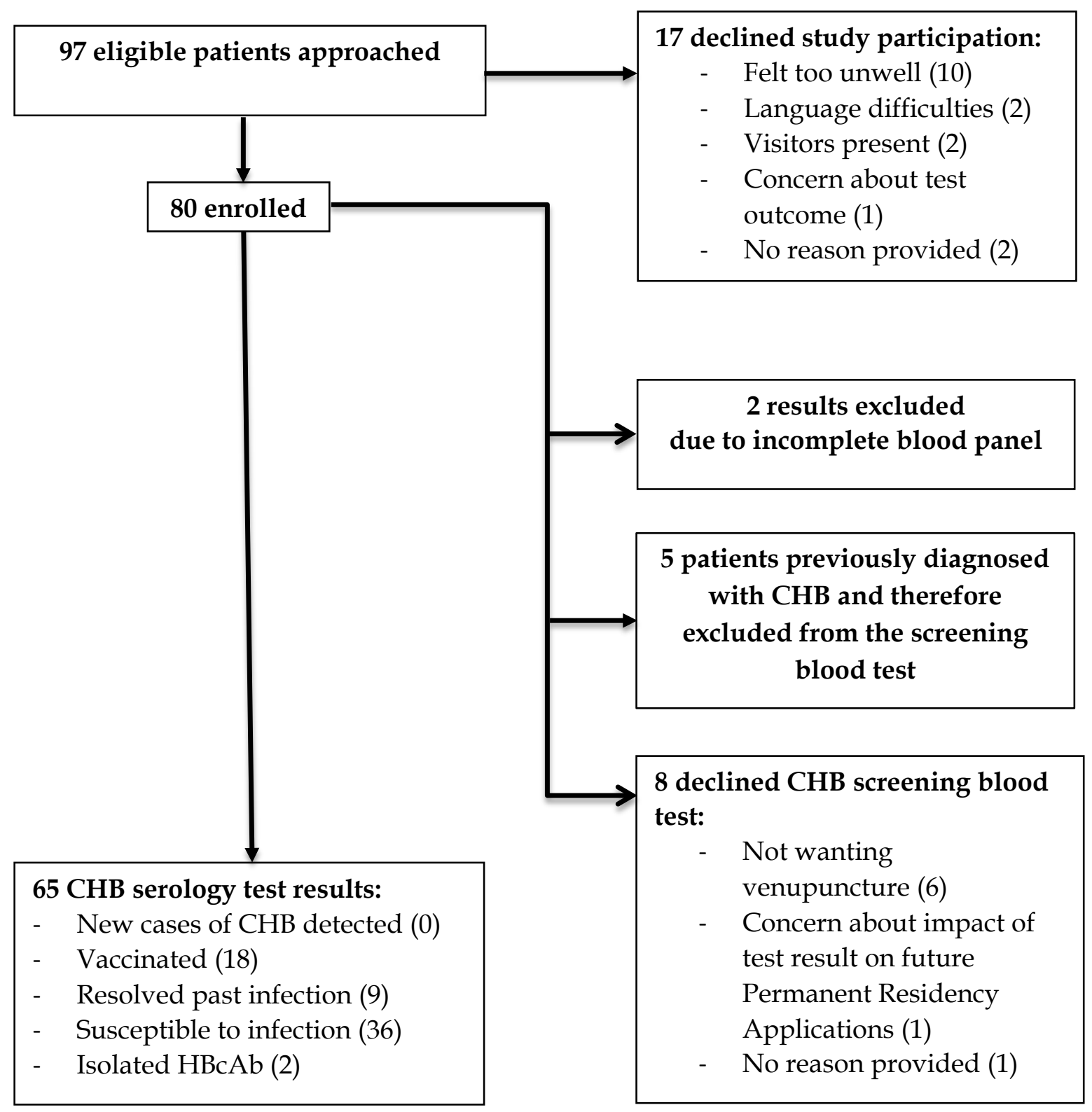


Figure 2. Comparison of the proportions of Emergency Department staff and patients who agreed/strongly agreed regarding suggested barriers to chronic hepatitis B screening. (ED Emergency Department, CHB chronic hepatitis B, Chi square comparisons reported)

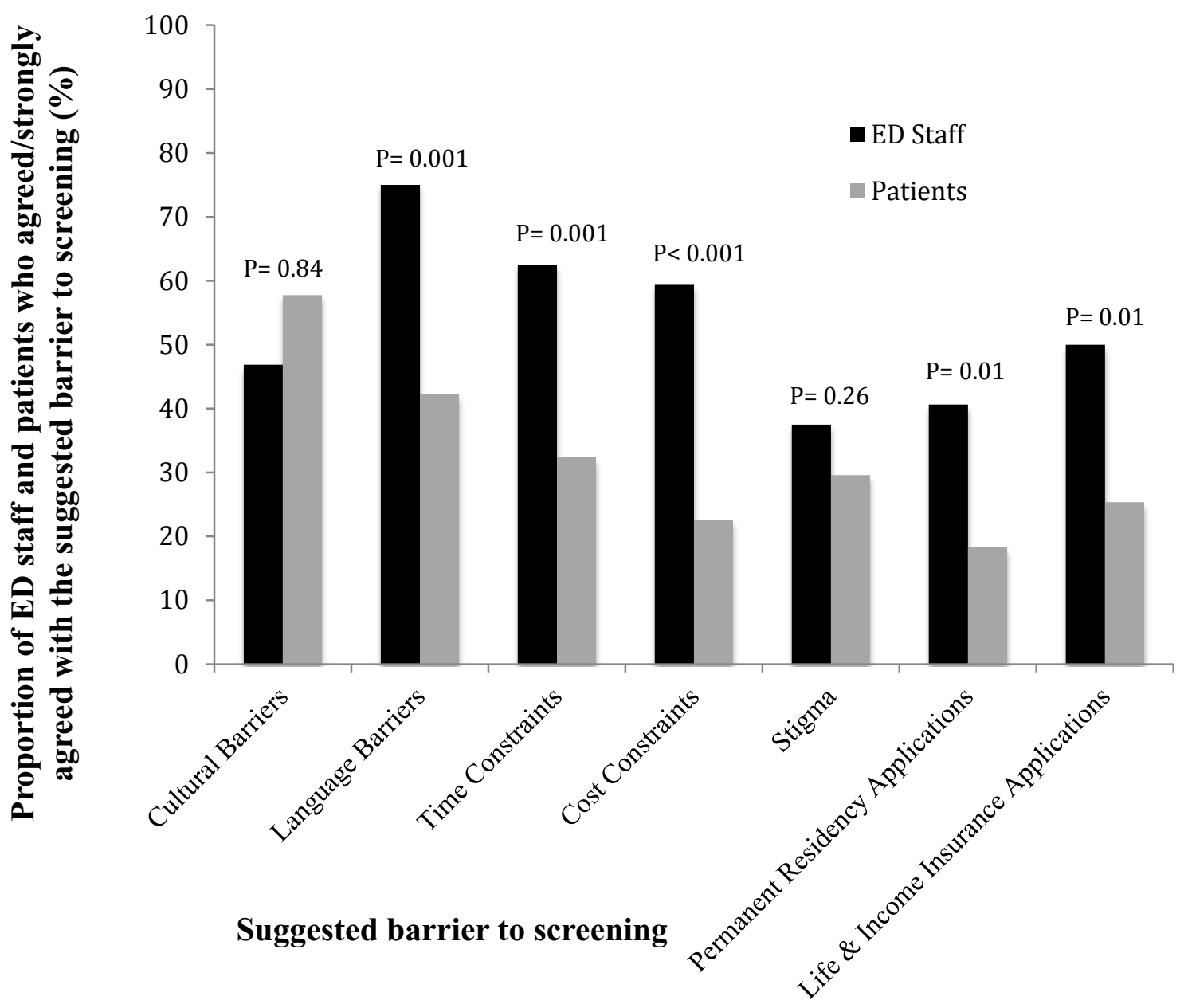




\title{
Exploring the feasibility of targeted Chronic Hepatitis B screening in the Emergency Department: a pilot study.
}

\author{
Dr Catherine Brock, BSc MD \\ Position: HMO1, Austin Health \\ Institutional affiliation: Austin Clinical School, Department of Medicine, University \\ of Melbourne
}

\author{
Dr Yuan Yi, BBiomed MD \\ Position: HMO2, Royal Melbourne Hospital \\ Institutional affiliation: Austin Clinical School, Department of Medicine, University \\ of Melbourne
}

\author{
Dr Timothy Papaluca, MBBS FRACP \\ Position: Gastroenterology Research Fellow, St Vincent's Health Melbourne \\ Institutional affiliation: Department of Gastroenterology and Hepatology, Austin \\ Health
}

\section{Benjamin Lucas, BSc M.Analytics}

Position: Master of Analytics student, Royal Melbourne Institute of Technology Institutional affiliation: Department of Geospatial Sciences and Mathematics, Royal Melbourne Institute of Technology

\section{Professor Peter W Angus, BS MB PhD}

Position: Medical Director, Liver Transplant Unit, Austin Health 
Institutional affiliation: Department of Medicine, University of Melbourne;

Department of Gastroenterology and Hepatology, Austin Health

\title{
Professor David Taylor, MBBS MD MPH DRCOG FACEM
}

Position: Director of Emergency Medicine Research, Austin Health

Institutional affiliation: Department of Medicine, University of Melbourne;

Department of Emergency Medicine, Austin Health

\author{
Dr Christopher Leung, MBBS FRACP PhD \\ Position: Gastroenterologist, Austin Health \\ Institutional affiliation: Department of Medicine, University of Melbourne; \\ Department of Gastroenterology and Hepatology, Austin Health
}

\begin{abstract}
Author contributions: Brock $\mathrm{C}$ assisted in the design of the study, performed data collection, was involved with data analysis, and drafted the manuscript; Yi Y assisted with study design and data collection; Papaluca $\mathrm{T}$ was involved with data collection; Lucas B performed statistical analysis; Angus P participated in oversight of the study; Taylor D assisted with oversight of the study, as well as study design, data analysis and manuscript draft; Leung $\mathrm{C}$ assisted with oversight of the study, as well as study design, data analysis and manuscript draft. The final manuscript has been read and approved by all authors.
\end{abstract}

Running title: Targeted Chronic Hepatitis B screening in ED

This article is protected by copyright. All rights reserved. 
Research carried out at: Austin Health, 145 Studley Rd, Heidelberg, Victoria, Australia, 3084.

Correspondence to: Dr Catherine Brock. BSc, MD

Austin Health, 145 Studley Rd, Heidelberg, Victoria, Australia, 3084.

Email: catherine.brock3@gmail.com | Telephone: +61 394965000

Word count

Abstract: 100

Main text: 750

This article is protected by copyright. All rights reserved. 


\section{University Library}

\section{- M M I N E R VA \\ A gateway to Melbourne's research publications}

Minerva Access is the Institutional Repository of The University of Melbourne

Author/s:

Brock, C;Yi, Y;Papaluca, T;Lucas, B;Angus, PW;Taylor, D;Leung, C

Title:

Exploring the feasibility of targeted chronic hepatitis B screening in the emergency department: A pilot study

Date:

2018-12-01

Citation:

Brock, C., Yi, Y., Papaluca, T., Lucas, B., Angus, P. W., Taylor, D. \& Leung, C. (2018). Exploring the feasibility of targeted chronic hepatitis B screening in the emergency department: A pilot study. EMERGENCY MEDICINE AUSTRALASIA, 30 (6), pp.864-866. https://doi.org/10.1111/1742-6723.13118.

Persistent Link:

http://hdl.handle.net/11343/284025 